\title{
Leaky Gut and Autoimmunity: An Intricate Balance in Individuals Health and the Diseased State
}

\author{
Bilal Ahmad Paray ${ }^{1}$, Mohammed Fahad Albeshr ${ }^{1}$, Arif Tasleem Jan ${ }^{2, *}$ and Irfan A. Rather ${ }^{3, *(\mathbb{D})}$ \\ 1 Department of Zoology, College of Science, King Saud University, P.O. Box 2455, Riyadh 11451, Saudi Arabia; \\ bparay@ksu.edu.sa (B.A.P.); albeshr@ksu.edu.sa (M.F.A.) \\ 2 School of Biosciences and Biotechnology, Baba Ghulam Shah Badshah University, Rajouri 185234, India \\ 3 Department of Biological Science, Faculty of Science, King Abdulaziz University, Jeddah 21589, Saudi Arabia \\ * Correspondence: atasleem@bgsbu.ac.in (A.T.J.); ammm@kau.edu.sa (I.A.R.)
}

Received: 11 November 2020; Accepted: 17 December 2020; Published: 21 December 2020

check for updates

\begin{abstract}
Damage to the tissue and the ruining of functions characterize autoimmune syndromes. This review centers around leaky gut syndromes and how they stimulate autoimmune pathogenesis. Lymphoid tissue commonly associated with the gut, together with the neuroendocrine network, collaborates with the intestinal epithelial wall, with its paracellular tight junctions, to maintain the balance, tolerance, and resistance to foreign/neo-antigens. The physiological regulator of paracellular tight junctions plays a vital role in transferring macromolecules across the intestinal barrier and thereby maintains immune response equilibrium. A new paradigm has explained the intricacies of disease development and proposed that the processes can be prevented if the interaction between the genetic factor and environmental causes is barred by re-instituting the intestinal wall function. The latest clinical evidence and animal models reinforce this current thought and offer the basis for innovative methodologies to thwart and treat autoimmune syndromes.
\end{abstract}

Keywords: autoimmune disorders; immune system; intestinal wall; microbiota

\section{Introduction}

The gastrointestinal (GI) tract's epithelium represents the largest mucosal lining that provides an interface between mammalian host and the external environment. The lumen of the gut harboring trillions of microbial inhabitants plays a vital role digestion and influences the immune system. The outstanding anatomical architecture of the GI fine-tunes processes like absorption and digestion of food, neuroendocrine networking, and immunological balance [1]. Despite being in continuous interaction with various foodborne pathogens and antigens, the GI lining very efficiently checks invasion by microorganisms and other molecules through its paracellular space, thereby maintaining its capability of intestinal permeability. The paracellular space size ranges approximately from 10 to $15 \AA$, implying that, under physiological situations, solutes with a molecular radius above $15 \AA$ $(\sim 3.5 \mathrm{kDa})$ have to be barred from the uptake path [2]. The transfer of macromolecules is controlled principally by epithelia's paracellular permeability, whose regulation is dependent on the attuned intercellular tight junctions [3]. A fast-rising number of illnesses, including autoimmune diseases, are reported due to intestinal permeability changes relative to changes in tight junctions (TJs) [4]. The change in permeability of the GI tract's epithelial lining creates an easy passage for commensal bacteria and their products from the lumen into the bloodstream (referred to as the leaky gut), thereby evoking immune response. Studies have well documented autoimmune diseases that arise due to the underlying phenomenal problem of the leaky gut $[5,6]$.

An autoimmune disease occurs when the immune system produces autoantibodies against self-antigens, causing assault on body tissue. An association of autoimmune diseases and leaky gut 
has emerged as a critical situation wherein the leakage of pathogens into the body system results in autoimmunity [6]. As such, maintenance of the healthy gut goes a long way in preventing autoimmune diseases. This review focuses on the relationship between the leaky gut and autoimmune diseases, causes of leaky gut, factors contributing to the healing of leaky gut, and a prospectus of ongoing research being carried out on the topic.

\section{Intestinal Barrier Regulation}

The single layer of epithelium in the intestinal wall acts as a barrier that separates the host body from the external environment. The regulation of a functional barrier is maintained by intestinal epithelial cells (IECs). The lining of IECs shows unique intercellular connections displaying TJs, desmosomes, and adherent junctions that allow nutrient and fluid absorption; however, it prevents the passing of unwanted microbes or antigens to the underlying tissue [7,8]. TJs are conceptualized as a dynamic structural barrier in the paracellular space [7], with protein composition that includes a major proportion of claudins, occluding, and junctional adhesion molecules (JAMs) [8]. Besides, the lamina propria of the intestinal epithelial system underneath the IECs holds a number of immune cells, not limited to T-cells, B-cells, macrophages, and dendritic cells. These cells play an essential role in maintaining intestinal homeostasis (Figure 1). The components of the immune system like tumor necrosis factor- $\alpha$ (TNF- $\alpha$ ), interleukins, and interferon- $\gamma$ are inevitable in the regulation of TJs. TNF- $\alpha$ mediated activation of NF- $\mathrm{KB}$ is one such important regulator, and studies have shown that the inhibition of the latter leads to protective effects against severe diarrhea [8].

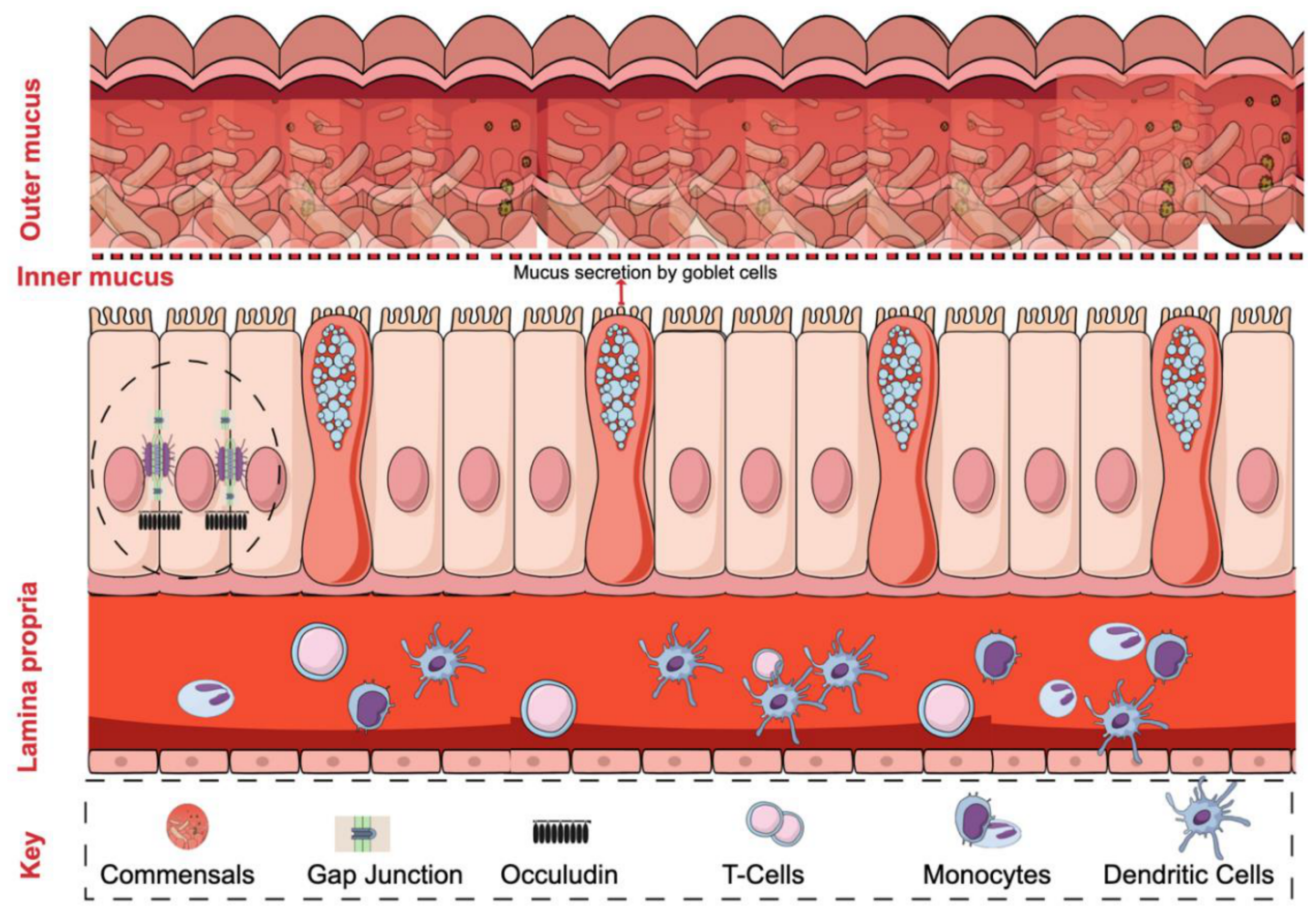

Figure 1. Schematic of the intestinal epithelial barrier. The lining of epithelial cells forms a barrier between the host body and the gut's lumen with commensal bacteria. The functional barrier cells are held together by many tight junction proteins that hinder the entry of bacteria. The mucosal layer acts as a first-line defense that prevents the contact of gut microbiome with intestinal epithelial cells. The role of immune cells against infection further maintains the hemostasis of the intestinal epithelial barrier.

Mucin, a highly glycosylated polymeric protein in the mucous layer, also plays an important role in trapping pathogens thereby preventing microbial colonization. The absence of a mucin layer, 
or a disturbed mucin layer has been seen to make animals vulnerable to intestinal inflammation [9]. The remarkable study on zonula occludens toxin (Zot) enterotoxin elaborated by Vibrio cholera showed that it reversibly opened TJs, which potentiated our knowledge of the regulation of the paracellular pathway [10]. Zonulin, being the eukaryotic counterpart, has been known to regulate TJs in relation to fluid and macromolecular movement and the exchange of leukocytes between the lumen of intestine and the bloodstream (by increasing intestinal permeability). Small intestines exposed to enteric bacteria secreted zonulin [11]. The role of zonulin in displaying innate immunity may represent a defensive mechanism that inhibits microorganisms that colonize the small intestine [11].

\section{Causes of Leaky Gut}

The cause of leaky gut includes prolonged contact with an environmental contaminant, overconsumption of alcoholic beverages, and unhealthy food choices [12]. Mental stress for an extended period inhibits the capacity of the immune system to respond speedily and slows down its ability to heal. The flow of blood to digestive organs is reduced, and there is an increase in the generation of toxic metabolites that cause a permanent deferral of the necessary repair routine [13]. The immune system responds to many places at once, and the parts of the body located far away from the intestinal system are easily affected.

The vertebrate GI tract comprises an extraordinary chemical composition and a thick microbial atmosphere, which influence the immune reactions of host cells and excite a rich medium of effector mechanisms involved in innate and acquired immune responses. Any perturbations in the structural dynamics of the microbial community and their functions within the intestinal tract (referred to as dysbiosis) also become a cause of leaky gut condition and, ultimately, the occurrence of autoimmune diseases [14]. Microbial inhabitants of the GI tract are unique in shaping the host's immunity and regulating metabolism [14]. Newly studied data specify a serious role of gut microbiota associated with autoimmune diseases [15,16]. Many Candida spp. on reaching the lining of the gastrointestinal wall cause collapse of the brush border epithelium lining the GI tract [17]. In addition, Salmonella sp., Giardia sp., Yersinia sp., Helicobacter pylori, Blastocystis hominids, Shigella sp., and other pathogenic microbes disrupt the intestinal lining, thereby causing gastrointestinal problems [18]. The digestive diseases or liver damage cases have amplified the propensity towards the leaky gut condition.

Beverages have few nutrients but take several nutrients to metabolize. The most notable of these nutrients are B-complex vitamins [13]. As part of metabolism in the liver, the contaminants are either broken down or stockpiled by the body. The abuse of overconsumption of beverages puts stress on the liver, which upsets the digestive ability and harms the GI tract [19]. Food with little fiber increases transit time, thereby increasing exposure to harmful by-products of digestion that cause irritation of the gut mucosa [20]. Additionally, processed foods contain many additives capable of promoting inflammation of the GI tract [20]. Non-steroidal medicines, aspirin, and Motrin mutilate the brush borders, permitting microbes, food particles that are not wholly digested, and contaminants to go into the bloodstream [13]. Birth control drugs and steroids also form favorable conditions for fungi nourishment, which cause damage to the lining. Chemotherapy and radiation treatments significantly disrupt the balance of the GI wall [21]. Additionally, sensitivity to certain foods and the environment could lead to the development of leaky gut syndrome [22,23].

\section{Factors Contributing to the Healing of Leaky Gut}

In the early 1860s, microbial intoxication of the gut was believed to be a major cause of systemic illnesses and mental disorders, and, for many decades, scientists agreed. Modern studies validate these allegations by illustrating that commensal microflora being recognized by Toll-like receptors (TLRs) is essential for promoting epithelial cell multiplication. Hence, it accelerates the healing of the surface epithelium after being damaged and impedes inflammation [24,25]. TLR signaling is critically vital for protection from pathogenic irritation and for promoting tolerant conditions to commensalism [26]. The gut microbiome interacts with the host cells under the influence of a highly regulated immune 
system that involves pattern recognition receptors (PRRs) like TLRs and NOD-like receptors (NLRs) [27]. The stimulation of TLRs boosts intestinal epithelial integrity through translocation of the tight junction protein zonula occludens-1 (ZO-1) $[26,28,29]$. A pathogen being acknowledged by specific TLRs results in several events, including the stimulation of NF- $\mathrm{KB}$ signaling that follows an increase in the production of cytokine and T-cell activation.

The mucosal structure is known for its natural resistance and capacity to differentiate possibly pathogenic bacteria from inoffensive antigens, which is realized via the arrangement of recognition receptors [26]. The permeability of the intestinal epithelium has also been well known to be modulated by the commensal microbiota and their productions [30]. The reversal of leaky gut through administration of probiotics and prebiotics has gained momentum in the last decade. Reviews confirm the reversal of leaky gut by probiotics through augmentation of TJ protein production [30]. Studies have shown that the fermentation activity of gut microbes exert healing effects not only on the intestinal epithelium integrity but also permeability [31]. Fermentation products have also been shown to modulate anti-inflammatory signals necessary for an adequate active immune response [32].

The gut shows diverse microbial communities in different parts. Streptococcaceae and Lactobacillaceae populate the proximal region, whereas the distal portion of the small intestine is home to Lactobacillaceae, Erysipelotrichaceae, and Enterobacteriaceae. The colon is inhabited by members of Bacteriodaceae, Prevotellaceae, and Clostridiaceae families. The epithelial lining of stomach harbors Lactobacillaceae and Streptococcaceae [33]. The term dysbiosis is commonly used to describe the situation that arises whenever there is a structural or functional change in gut microbiota configuration, which disturbs homeostasis of the gut [33]. Fermentation products are also known to become imbalanced under dysbiosis. The infection-destroying segments of microbiota may altogether be countered with inflammation-aggravating germs, improving the wall effect of the gastrointestinal mucosa and straightening the interaction with inflammation-causing constituents of the immune system [34]. As further studies show, regulating the immune system is one way of fixing a leaky gut $[35,36]$. Dysbiosis upregulates the expression of TLRs on antigen-presenting cells (APCs) and disturbs the T-cell balance [37]. Reports indicate that dysbiosis promotes the production of neo-antigenic determinants of self-proteins, thereby evoking autoimmunity [38].

\section{Autoimmune Diseases Associated with Leaky Gut}

The epithelial lining of the gastrointestinal mucosa acts as a barrier against the gut luminal content, thereby preventing the passage of elements that can cause harm to the host system [13]. A breach in the epithelial barrier by foreign entities from the lumen into the host sets out a series of events that turns the immune system against the host itself, thereby presenting a plethora of autoimmune diseases like type 1 diabetes (T1D), multiple sclerosis (MS), inflammatory bowel disease (IBD), systemic lupus erythematosus (SLE), etc. [4,39] (Figure 2).

The situation of impaired barrier function in the mucosal lining of the GI tract, which results in even larger holes in the lining, manifests in leaky gut. Thus, things that were initially barred from passing through (e.g., proteins, gluten, microbes, and food antigens) can now breach through the tissue as well as systemic circulation, resulting in intestinal inflammation that may trigger an array of autoimmune diseases such as inflammatory bowel disease, celiac diseases, autoimmune hepatitis, multiple sclerosis, etc. [4,40-44]. We have accumulating evidence in support of the presence of overexpressed zonulin in subjects with autoimmune diseases [41]. Zonulin has been recognized as pre-haptoglobin (HP)2 [45]. The release of zonulin has been implicated in the pathogenesis of autoimmune diseases where the stimuli are bacteria, both the gut commensals and pathogens, and food antigens like gluten [6]. Under the conditions of compromised TJ function, an immune response ensues after antigen stimulation. The immune cells such as antigen-presenting cells (APCs), T-cells, T killer cells, B-cells, and plasma cells in the intestinal barrier get activated [6]. Dysbiosis induced by leaky gut presents an inflammatory environment that paves the way to autoimmunity. Microbial translocation induces pro-inflammatory cytokines such as IFN- $\gamma$, TNF- $\alpha$, and IL-13 [37]. 
Herein we present a brief account of some of the known autoimmune diseases due to their connection with leaky gut syndrome with evidence supporting the paradigm that leaky gut causes autoimmunity [46].

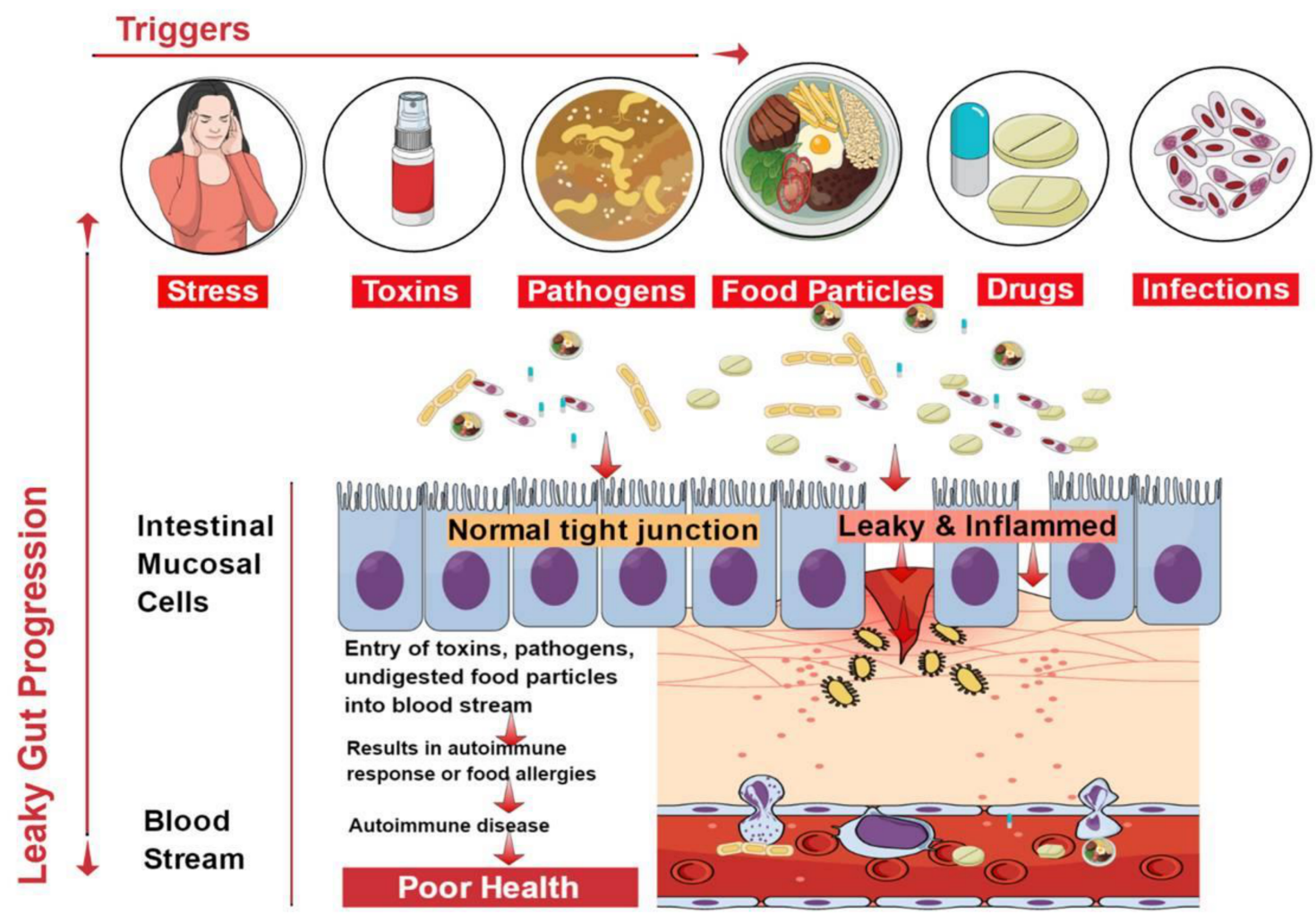

Figure 2. Factors contributing to the development of leaky gut and its relationship to autoimmune diseases. Diet, genetic susceptibility, and environmental conditions, among others, affect the intestinal epithelial barrier integrity. This imbalance leads to compromised barrier integrity and contributes to several diseases.

\subsection{Type 1 Diabetes}

T1D, an autoimmune disease mediated by self-reactive T-cells, is characterized by the destruction of insulin-producing $\beta$-cells in the host's pancreas $[47,48]$. GI signs of diabetes mellitus have widely been attributed to the changed intestinal permeability secondary to autonomic neuropathy $[49,50]$. However, suggestions from other studies indicate that an increase in the permeability of the intestinal tight junctions is accountable for the start of the ailment, and GI symptoms are regularly experienced by these patients [51]. Studies in T1D models have confirmed that changes in the gut wall (of the large intestine) help the luminal bacteria breach into the extraluminal tissues [52]. This hypothesis is reinforced by a clinical study carried out in humans and on a diabetic animal model [53-56]. In one study, an increase in a rat's small intestine permeability preceded the onset of diabetes by no less than a month [57]. Reports show that increased local permeability of the intestinal mucosa showed an increase in proinflammatory cytokines leading to a deranged immune system [49]. In both human and animal studies, gliadin, acting as an antigen, is a trigging factor connected to the autoimmunity of T1D [58].

Studies have attested that the pathogenesis of T1D displays an altered gut microbiome and, hence, dysbiosis [27]. Data support that gut bacteria can profoundly affect the prevention of autoimmune diabetes [27]. Leaky gut induced dysbiosis causes translocation of gut bacteria into pancreatic lymph nodes, whereby induction of pathogenic T helper cells contributes to T1D [27]. Gut microflora was found to protect against the development of T1D in two animal models, bio-breeding disease-prone 
(BB-DP) rats, and non-obese diabetic (NOD) mice [59,60]. Moreover, GI microbiota changes [61] and the use of zonulin inhibitors were found to ameliorate the manifestation of T1D in rat models of the disease $[11,57,62]$.

\subsection{Multiple Sclerosis}

Apart from an increase in the permeability of the blood-brain barrier, subjects with multiple sclerosis were found to exhibit an increased permeability at intestinal tight junctions [7]. A quarter of patients with multiple sclerosis had an increased permeability of the intestinal walls [40]. Multiple sclerosis and Crohn's disease patients exhibit an increase in the number of peripheral B cells, a sign of antigen exposure. This further reinforces the notion of preexisting, genetic abnormalities in the permeability of the small intestine, with a consequently changed antigen exposure as a pathogenic issue common to the two diseases [40]. Bacterial infections are believed to cause multiple sclerosis, though clear epidemiological evidence is lacking. This supports the notion that commensal bacteria contribute to MS pathogenesis, and the effects of nutrition on MS advancements provide various forms of indirect evidence $[63,64]$. Experimental autoimmune encephalomyelitis (EAE), an animal model of MS, suggests that the gut flora contributes to the development of this illness, and therapy involves administration of probiotics (i.e., live beneficial bacteria) or prebiotics (i.e., compounds that stimulate the growth of beneficial bacteria) [65]. EAE is usually induced in experimental animals by immunization with myelin antigens in a blend with a potent adjuvant [63]. In contrast, stomach treatment with a combination of antibiotics reduced the severity of EAE [63]. Attenuation of the pro-inflammatory TH1/TH17 responses helps in reducing the impact of the demyelinating syndrome. Lee and colleagues demonstrated that disease defense in germ-free mice matched with lowered levels of the pro-inflammatory cytokines IL-17 and IFN-c and raised numbers of Forkhead box P3+ (Foxp3+) regulatory $\mathrm{T}$ (Treg) cells in peripheral lymphoid tissues and the CNS [66]. Moreover, IL-10-producing, Foxp3+ Treg cells, which accumulate in the cervical LNs (cLNs) of antibiotic-treated mice, could protect innocent recipients from the transfer of EAE. We have accumulating evidence in support of dysbiosis in MS [67].

\subsection{Inflammatory Bowel Diseases}

IBD, which involves Crohn's disease (CD) and ulcerative colitis (UC), occurs due to defects in the paracellular permeability of the GI tract [68]. The pathogenesis of IBD is multifactorial. In recent years, substantial evidence has supported the theory that environmental, genetic, and immunological factors instigate the autoimmune course [69]. Despite this, most evidence suggests the contribution of increased gastric permeability to the pathogenesis of IBD [70]. In Crohn's disease, an increase in the permeability of the intestinal epithelial comes before clinical relapse, which suggests that a defect in permeability is the first event in the occurrence of the disease [71,72]. Reports suggest that during the development of IBD, a defective intestinal barrier displays the expression of cytokines, IFN- $\gamma$, and TNF- $\alpha$, thereby initiating inflammation [73]. Paradoxically, this presents a situation wherein the deranged immune system in the intestinal tissue triggers further leaks in the luminal wall. The condition of dysbiosis plays an important role in the pathogenesis of IBD [74]. The dysbiosis in IBD is seen as an imbalance arising in the densities of obligate and facultative anaerobes that result in the pathogenesis of IBD [75].

\subsection{Ankylosing Spondylitis}

Ankylosing spondylitis (AS) is a common rheumatic syndrome that distinctively affects young adults. It is characterized by a stiff and painful back [76]. The connection between an increase in the permeability of the intestines and the syndrome has been plainly established [77]. Using a proteomic method, an investigation of the serum protein summaries of AS patients and healthy controls from a Chinese AS family has been conducted. A group of four massively expressed protein spots was clearly witnessed in every AS patient's summary and consequently recognized as isoforms of HP [69]. 
The role of dysbiosis in AS has been demonstrated by showing the active participation of ileal bacteria in modulating local and systemic immune responses [78]. The gut vasculature showed impairment that caused a significant rise in zonulin levels, which affected the TJs.

\subsection{Systemic Lupus Erythematosus}

SLE, a prototypical multisystem autoimmune disease characterized by a hyperactive immune response that causes severe and persistent inflammation, often leads to multiorganelle damage [79]. Though the etiology of SLE is unclear, various genetic and environmental factors are involved in the occurrence of the disease [80]. Increased bacterial lipopolysaccharide (LPS) uptake via the gut lumen promotes the development and progression of SLE [5]. The addition of TLR4 activation, with LPS inducing the release of CD14 from monocytes, exacerbates SLE development [24,25,81]. Dysbiosis induced by leaky gut enhances inflammatory macrophagic activity that damages the tissues in SLE [27]. Enhancement in the commensal gut microbiota through supplementation of probiotics significantly ameliorates the occurrence of the disease $[79,82,83]$.

\subsection{Healing the Leaky Gut}

Many studies have revealed that a leaky gut paves the way to the development of autoimmune diseases. Therefore, healing the leaky gut suppresses the symptoms of these diseases; as such, decreasing its occurrence is vital to the prevention of autoimmune diseases [84,85]. The process of healing the gut has also been looked into, with both short-term and long-term measures. Short-term measures to heal the gut include discontinuing foods rich in gluten, dairy, and sugar from the diet [86]. Additionally, raw foods eaten in moderation and consumption of tea and bone broth are vital to healing [87]. In the long term, maintaining good gut health is crucial to the prevention of autoimmune diseases by sustaining proper gut health. Similarly, terraforming is a long-term method of preventing leaky gut. Furthermore, the addition of prebiotics helps in establishing the gut flora by creating a fresh system of operation in the gut [87]. Thus, the inclusion of probiotics and prebiotics in the daily diet can augment gut microbiome health by reducing intestinal permeability [5].

Treatment with Bacteroides fragilis has been shown to decrease the pathogen translocation that further ameliorates the diseased state [5]. The role of $B$. fragilis has been predominantly shown to change the microbial flora and improve the barrier function of the intestine. As most autoimmune diseases involve the imbalance of the microbiota and hyperactivity of the immune system, systemic immune modulation through an extraneous supply of substances that either supplement internal microbiota or promote their proliferation is possible $[88,89]$. One such measure to increase resident microflora has been achieved using probiotics and prebiotics [89]. Probiotics (i.e., healthy microflora) and prebiotics (i.e., food compounds promoting the proliferation of probiotics) improve the gut environment on administration, prevent the colonization of pathogenic microbes, and regulate immune function. They reduce the permeability of the gut lining and, as such, confer health benefits to the host. The introduction of probiotics (most of the lactobacilli) modulates the gut microbiota and decreases the occurrence of autoimmune diseases such as IBD and T1D [89,90]. The most common prebiotic supplement derived from plants is inulin. The supplementation of diet with inulin enhances the growth of Bifidobacterium spp., besides improving glucose homeostasis [91,92].

\section{Conclusions}

Autoimmune disorders are facilitated by heredity, the environment, contaminants, and altered gut microbiota. Acting as fueling forces in the facilitation of autoimmune disorders, there has been fantastic advancement in our understanding of the interplay among these factors. Genetic predisposition, exposure to triggering environmental factors, and damage to intestinal wall function, secondary to poor functioning of paracellular tight junctions, appear to be crucial ingredients presented in the pathogenesis of autoimmune diseases. The traditional model of autoimmune pathogenesis relating to a particular genetic constitution and contact with environmental triggers has lately been challenged 
by the inclusion of a third component: damaged GI function. In T1D, gliadin can contribute to the loss of stomach wall function and can prompt the autoimmune reaction in genetically prone persons. This recent theory suggests that as soon as the autoimmune process is triggered, it is not auto-continuing, but can rather be moderated or even overturned by inhibiting the constant interplay between the genetic factor and the environment. Since tight junctions are components of reduced functioning in this interaction, new healing approaches are aimed at reinventing the gut barrier function, providing inventive, unexplored methods for the treatment of these cataclysmic diseases. We emphasize on more studies involving the application of probiotics that can show the reversal of dysbiosis aiming at disease attenuation. Keeping in view of the cost-effectiveness of these treatment modalities, autoimmune diseases in coherence with leaky gut can be well handled, and we sincerely foresee a future approach to focus on more of such studies.

Author Contributions: B.A.P., M.F.A., I.A.R. and A.T.J. conceived the idea and contributed to writing the manuscript. B.A.P. and M.F.A. contributed to designing the paper and literature survey. I.A.R. designed the figures. A.T.J. and I.A.R. critically reviewed, edited, and finalized the manuscript for submission. All authors have read and agreed to the published version of the manuscript.

Funding: This research was funded by the Deputyship for Research and Innovation, "Ministry of Education" in Saudi Arabia, through the Project no. (IFKSURP-211).

Acknowledgments: The authors extend their appreciation to the Deputyship for Research and Innovation, "Ministry of Education" in Saudi Arabia, through the Project no. (IFKSURP-211).

Conflicts of Interest: The authors declare no conflict of interest.

\section{References}

1. Tomomasa, T.; Kuroume, T.; Arai, H.; Wakabayashi, K.; Itoh, Z. Erythromycin induces migrating motor complex in human gastrointestinal tract. Dig. Dis. Sci. 1986, 31, 157-161. [CrossRef]

2. Christen, U.; von Herrath, M.G. Induction, acceleration or prevention of autoimmunity by molecular mimicry. Mol. Immunol. 2004, 40, 1113-1120. [CrossRef]

3. Tripathi, A.; Lammers, K.M.; Goldblum, S.; Shea-Donohue, T.; Netzel-Arnett, S.; Buzza, M.S.; Antalis, T.M.; Vogel, S.N.; Zhao, A.; Yang, S.; et al. Identification of human zonulin, a physiological modulator of tight junctions, as prehaptoglobin-2. Proc. Natl. Acad. Sci. USA 2009, 106, 16799-16804. [CrossRef]

4. Fasano, A.; Baudry, B.; Pumplin, D.W.; Wasserman, S.S.; Tall, B.D.; Ketley, J.M.; Kaper, J.B. Vibrio cholerae produces a second enterotoxin, which affects intestinal tight junctions. Proc. Natl. Acad. Sci. USA 1991, 88, 5242-5246. [CrossRef]

5. Mu, Q.; Kirby, J.; Reilly, C.M.; Luo, X.M. Leaky gut as a danger signal for autoimmune diseases. Front. Immunol. 2017, 8, 598. [CrossRef] [PubMed]

6. Fasano, A. Zonulin and its regulation of intestinal barrier function: The biological door to inflammation, autoimmunity, and cancer. Physiol. Rev. 2011, 91, 151-175. [CrossRef] [PubMed]

7. Anderson, J.M.; Van Itallie, C.M. Physiology and function of the tight junction. Cold Spring Harb. Perspect Biol. 2009, 1, a002584. [CrossRef] [PubMed]

8. Chelakkot, C.; Ghim, J.; Ryu, S.H. Mechanisms regulating intestinal barrier integrity and its pathological implications. Exp. Mol. Med. 2018, 50, 103. [CrossRef]

9. Boltin, D.; Perets, T.T.; Vilkin, A.; Niv, Y. Mucin function in inflammatory bowel disease: An update. J. Clin. Gastroenterol. 2013, 47, 106-111. [CrossRef]

10. Fasano, A.; Fiorentini, C.; Donelli, G.; Uzzau, S.; Kaper, J.B.; Margaretten, K.; Ding, X.; Guandalini, S.; Comstock, L.; Goldblum, S.E. Zonula occludens toxin modulates tight junctions through protein kinase c-dependent actin reorganization, in vitro. J. Clin. Investig. 1995, 96, 710-720. [CrossRef]

11. El Asmar, R.; Panigrahi, P.; Bamford, P.; Berti, I.; Not, T.; Coppa, G.V.; Catassi, C.; Fasano, A. Host-dependent zonulin secretion causes the impairment of the small intestine barrier function after bacterial exposure. Gastroenterology 2002, 123, 1607-1615. [CrossRef] [PubMed]

12. Schmidt, T.C.; Schirmer, M.; Weiss, H.; Haderlein, S.B. Microbial degradation of methyl tert-butyl ether and tert-butyl alcohol in the subsurface. J. Contam. Hydrol. 2004, 70, 173-203. [CrossRef] [PubMed]

13. Fasano, A. Intestinal zonulin: Open sesame! Gut 2001, 49, 159-162. [CrossRef] [PubMed] 
14. Meddings, J.B.; Jarand, J.; Urbanski, S.J.; Hardin, J.; Gall, D.G. Increased gastrointestinal permeability is an early lesion in the spontaneously diabetic bb rat. Am. J. Physiol. 1999, 276, G951-G957. [CrossRef]

15. De Luca, F.; Shoenfeld, Y. The microbiome in autoimmune diseases. Clin. Exp. Immunol. 2019, 195, 74-85. [CrossRef]

16. Nikitakis, N.G.; Papaioannou, W.; Sakkas, L.I.; Kousvelari, E. The autoimmunity-oral microbiome connection. Oral Dis. 2017, 23, 828-839. [CrossRef]

17. Yan, L.; Yang, C.; Tang, J. Disruption of the intestinal mucosal barrier in candida albicans infections. Microbiol. Res. 2013, 168, 389-395. [CrossRef]

18. Qin, J.; Li, R.; Raes, J.; Arumugam, M.; Burgdorf, K.S.; Manichanh, C.; Nielsen, T.; Pons, N.; Levenez, F.; Yamada, T.; et al. A human gut microbial gene catalogue established by metagenomic sequencing. Nature 2010, 464, 59-65. [CrossRef]

19. Bishehsari, F.; Magno, E.; Swanson, G.; Desai, V.; Voigt, R.M.; Forsyth, C.B.; Keshavarzian, A. Alcohol and gut-derived inflammation. Alcohol Res. 2017, 38, 163-171.

20. Conlon, M.A.; Bird, A.R. The impact of diet and lifestyle on gut microbiota and human health. Nutrients 2014, 7, 17-44. [CrossRef]

21. Fasano, A. Physiological, pathological, and therapeutic implications of zonulin-mediated intestinal barrier modulation: Living life on the edge of the wall. Am. J. Pathol. 2008, 173, 1243-1252. [CrossRef] [PubMed]

22. Fritscher-Ravens, A.; Schuppan, D.; Ellrichmann, M.; Schoch, S.; Rocken, C.; Brasch, J.; Bethge, J.; Bottner, M.; Klose, J.; Milla, P.J. Confocal endomicroscopy shows food-associated changes in the intestinal mucosa of patients with irritable bowel syndrome. Gastroenterology 2014, 147, 1012-1020.e1014. [CrossRef] [PubMed]

23. Vazquez-Roque, M.I.; Camilleri, M.; Smyrk, T.; Murray, J.A.; Marietta, E.; O’Neill, J.; Carlson, P.; Lamsam, J.; Janzow, D.; Eckert, D.; et al. A controlled trial of gluten-free diet in patients with irritable bowel syndrome-diarrhea: Effects on bowel frequency and intestinal function. Gastroenterology 2013, 144, 903-911.e903. [CrossRef] [PubMed]

24. Lee, T.P.; Huang, J.C.; Liu, C.J.; Chen, H.J.; Chen, Y.H.; Tsai, Y.T.; Yang, W.; Sun, K.H. Interactions of surface-expressed tlr-4 and endosomal tlr-9 accelerate lupus progression in anti-dsdna antibody transgenic mice. Exp. Biol. Med. 2014, 239, 715-723. [CrossRef] [PubMed]

25. Lee, T.P.; Tang, S.J.; Wu, M.F.; Song, Y.C.; Yu, C.L.; Sun, K.H. Transgenic overexpression of anti-double-stranded DNA autoantibody and activation of toll-like receptor 4 in mice induce severe systemic lupus erythematosus syndromes. J. Autoimmun. 2010, 35, 358-367. [CrossRef] [PubMed]

26. Abreu, M.T. Toll-like receptor signalling in the intestinal epithelium: How bacterial recognition shapes intestinal function. Nat. Rev. Immunol. 2010, 10, 131-144. [CrossRef]

27. Abdellatif, A.M.; Sarvetnick, N.E. Current understanding of the role of gut dysbiosis in type 1 diabetes. J. Diabetes 2019, 11, 632-644. [CrossRef]

28. Cereijido, M.; Anderson, J. Evolution of ideas on the tight junction. In Tight Junctions; Cereijido, M., Anderson, J., Eds.; CRC Press: Boca Raton, FL, USA, 2011; pp. 1-18.

29. Wang, W.; Uzzau, S.; Goldblum, S.E.; Fasano, A. Human zonulin, a potential modulator of intestinal tight junctions. J. Cell Sci. 2000, 113 Pt 24, 4435-4440.

30. Pham, V.T.; Seifert, N.; Richard, N.; Raederstorff, D.; Steinert, R.E.; Prudence, K.; Mohajeri, M.H. The effects of fermentation products of prebiotic fibres on gut barrier and immune functions in vitro. PeerJ 2018, 6, e5288. [CrossRef]

31. Mariadason, J.M.; Barkla, D.H.; Gibson, P.R. Effect of short-chain fatty acids on paracellular permeability in caco-2 intestinal epithelium model. Am. J. Physiol. 1997, 272, G705-G712. [CrossRef]

32. Buckley, K.M.; Rast, J.P. An organismal model for gene regulatory networks in the gut-associated immune response. Front. Immunol. 2017, 8, 1297. [CrossRef] [PubMed]

33. Dutta, S.K.; Verma, S.; Jain, V.; Surapaneni, B.K.; Vinayek, R.; Phillips, L.; Nair, P.P. Parkinson's disease: The emerging role of gut dysbiosis, antibiotics, probiotics, and fecal microbiota transplantation. J. Neurogastroenterol. Motil. 2019, 25, 363-376. [CrossRef] [PubMed]

34. Hakansson, A.; Molin, G. Gut microbiota and inflammation. Nutrients 2011, 3, 637-682. [CrossRef] [PubMed]

35. Branski, D.; Fasano, A.; Troncone, R. Latest developments in the pathogenesis and treatment of celiac disease. J. Pediatr. 2006, 149, 295-300. [CrossRef] [PubMed]

36. Jabri, B.; Sollid, L.M. Tissue-mediated control of immunopathology in coeliac disease. Nat. Rev. Immunol. 2009, 9, 858-870. [CrossRef] [PubMed] 
37. Abdelhamid, L.; Luo, X.M. Retinoic acid, leaky gut, and autoimmune diseases. Nutrients 2018, $10,1016$. [CrossRef]

38. Opdenakker, G.; Proost, P.; Van Damme, J. Microbiomic and posttranslational modifications as preludes to autoimmune diseases. Trends Mol. Med. 2016, 22, 746-757. [CrossRef]

39. Mu, Q.; Zhang, H.; Luo, X.M. Sle: Another autoimmune disorder influenced by microbes and diet? Front. Immunol. 2016, 6, 608. [CrossRef]

40. Fasano, A.; Shea-Donohue, T. Mechanisms of disease: The role of intestinal barrier function in the pathogenesis of gastrointestinal autoimmune diseases. Nat. Clin. Pract. Gastroenterol. Hepatol. 2005, 2, 416-422. [CrossRef]

41. Khaleghi, S.; Ju, J.M.; Lamba, A.; Murray, J.A. The potential utility of tight junction regulation in celiac disease: Focus on larazotide acetate. Ther. Adv. Gastroenterol. 2016, 9, 37-49. [CrossRef]

42. Lin, R.; Zhou, L.; Zhang, J.; Wang, B. Abnormal intestinal permeability and microbiota in patients with autoimmune hepatitis. Int. J. Clin. Exp. Pathol. 2015, 8, 5153-5160. [PubMed]

43. Van der Waals, M.J.; Pijls, C.; Sinke, A.J.C.; Langenhoff, A.A.M.; Smidt, H.; Gerritse, J. Anaerobic degradation of a mixture of MtBE, EtBE, TBA, and Benzene under different redox condition. Appl. Microbiol. Biotechnol. 2018, 102, 3387-3397. [CrossRef] [PubMed]

44. Tlaskalova-Hogenova, H.; Stepankova, R.; Kozakova, H.; Hudcovic, T.; Vannucci, L.; Tuckova, L.; Rossmann, P.; Hrncir, T.; Kverka, M.; Zakostelska, Z.; et al. The role of gut microbiota (commensal bacteria) and the mucosal barrier in the pathogenesis of inflammatory and autoimmune diseases and cancer: Contribution of germ-free and gnotobiotic animal models of human diseases. Cell Mol. Immunol. 2011, 8, 110-120. [CrossRef] [PubMed]

45. Fasano, A. Leaky gut and autoimmune diseases. Clin. Rev. Allergy Immunol. 2012, 42, 71-78. [CrossRef]

46. Campbell, A.W. Autoimmunity and the Gut. Autoimmune Dis. 2014, 2014, 152428. [CrossRef]

47. Brown, E.M.; Kenny, D.J.; Xavier, R.J. Gut microbiota regulation of $\mathrm{t}$ cells during inflammation and autoimmunity. Annu. Rev. Immunol. 2019, 37, 599-624. [CrossRef]

48. Sekirov, I.; Russell, S.L.; Antunes, L.C.; Finlay, B.B. Gut microbiota in health and disease. Physiol. Rev. 2010, 90, 859-904. [CrossRef]

49. Carratu, R.; Secondulfo, M.; de Magistris, L.; Iafusco, D.; Urio, A.; Carbone, M.G.; Pontoni, G.; Carteni, M.; Prisco, F. Altered intestinal permeability to mannitol in diabetes mellitus type I. J. Pediatr. Gastroenterol. Nutr. 1999, 28, 264-269. [CrossRef]

50. Li, X.; Atkinson, M.A. The role for gut permeability in the pathogenesis of type 1 diabetes-a solid or leaky concept? Pediatr. Diabetes 2015, 16, 485-492. [CrossRef]

51. Yacyshyn, V.J.; Thatipelli, M.R.; Lennon, R.J.; Bailey, K.R.; Stanson, A.W.; Holmes, D.R., Jr.; Gloviczki, P. Predictors of failure of endovascular therapy for peripheral arterial disease. Angiology 2006, 57, 403-417. [CrossRef]

52. Peters, A.; Wekerle, H. Autoimmune diabetes mellitus and the leaky gut. Proc. Natl. Acad. Sci. USA 2019, 116, 14788-14790. [CrossRef] [PubMed]

53. Collin, P.; Salmi, J.; Hallstrom, O.; Oksa, H.; Oksala, H.; Maki, M.; Reunala, T. High frequency of coeliac disease in adult patients with type-i diabetes. Scand. J. Gastroenterol. 1989, 24, 81-84. [CrossRef] [PubMed]

54. Damci, T.; Nuhoglu, I.; Devranoglu, G.; Osar, Z.; Demir, M.; Ilkova, H. Increased intestinal permeability as a cause of fluctuating postprandial blood glucose levels in type 1 diabetic patients. Eur. J. Clin. Investig. 2003, 33, 397-401. [CrossRef] [PubMed]

55. Paruk, I.M.; Naidoo, V.G.; Pirie, F.J.; Maharaj, S.; Nkwanyana, N.M.; Dinnematin, H.L.; Ganie, Y.; Ramdial, P.K.; Motala, A.A. Prevalence and characteristics of celiac disease in south african patients with type 1 diabetes mellitus: Results from the durban diabetes and celiac disease study. J. Gastroenterol. Hepatol. 2019, 34, 673-678. [CrossRef] [PubMed]

56. Secondulfo, M.; Iafusco, D.; Carratu, R.; de Magistris, L.; Sapone, A.; Generoso, M.; Mezzogiomo, A.; Sasso, F.C.; Carteni, M.; De Rosa, R.; et al. Ultrastructural mucosal alterations and increased intestinal permeability in non-celiac, type I diabetic patients. Dig. Liver Dis. 2004, 36, 35-45. [CrossRef]

57. Watts, T.; Berti, I.; Sapone, A.; Gerarduzzi, T.; Not, T.; Zielke, R.; Fasano, A. Role of the intestinal tight junction modulator zonulin in the pathogenesis of type I diabetes in bb diabetic-prone rats. Proc. Natl. Acad. Sci. USA 2005, 102, 2916-2921. [CrossRef] 
58. Auricchio, R.; Paparo, F.; Maglio, M.; Franzese, A.; Lombardi, F.; Valerio, G.; Nardone, G.; Percopo, S.; Greco, L.; Troncone, R. In vitro-deranged intestinal immune response to gliadin in type 1 diabetes. Diabetes 2004, 53, 1680-1683. [CrossRef]

59. Scott, F.W. Food-induced type 1 diabetes in the bb rat. Diabetes Metab. Rev. 1996, 12, 341-359. [CrossRef]

60. Hansen, A.K.; Ling, F.; Kaas, A.; Funda, D.P.; Farlov, H.; Buschard, K. Diabetes preventive gluten-free diet decreases the number of caecal bacteria in non-obese diabetic mice. Diabetes Metab. Res. Rev. 2006, 22, 220-225. [CrossRef]

61. Li, B.; Selmi, C.; Tang, R.; Gershwin, M.E.; Ma, X. The microbiome and autoimmunity: A paradigm from the gut-liver axis. Cell Mol. Immunol. 2018, 15, 595-609. [CrossRef]

62. Liang, Y.; Wang, X.; He, D.; You, Q.; Zhang, T.; Dong, W.; Fei, J.; Xing, Y.; Wu, J. Ameliorating gut microenvironment through staphylococcal nuclease-mediated intestinal nets degradation for prevention of type 1 diabetes in nod mice. Life Sci. 2019, 221, 301-310. [CrossRef] [PubMed]

63. Westall, F.C. Abnormal hormonal control of gut hydrolytic enzymes causes autoimmune attack on the cns by production of immune-mimic and adjuvant molecules: A comprehensive explanation for the induction of multiple sclerosis. Med. Hypotheses 2007, 68, 364-369. [CrossRef] [PubMed]

64. Yokote, H.; Miyake, S.; Croxford, J.L.; Oki, S.; Mizusawa, H.; Yamamura, T. Nkt cell-dependent amelioration of a mouse model of multiple sclerosis by altering gut flora. Am. J. Pathol. 2008, 173, 1714-1723. [CrossRef] [PubMed]

65. Hooper, L.V.; Littman, D.R.; Macpherson, A.J. Interactions between the microbiota and the immune system. Science 2012, 336, 1268-1273. [CrossRef]

66. Lee, Y.K.; Menezes, J.S.; Umesaki, Y.; Mazmanian, S.K. Proinflammatory t-cell responses to gut microbiota promote experimental autoimmune encephalomyelitis. Proc. Natl. Acad. Sci. USA 2011, 108 (Suppl. 1), 4615-4622. [CrossRef]

67. Chu, F.; Shi, M.; Lang, Y.; Shen, D.; Jin, T.; Zhu, J.; Cui, L. Gut microbiota in multiple sclerosis and experimental autoimmune encephalomyelitis: Current applications and future perspectives. Mediat. Inflamm. 2018, 8168717. [CrossRef]

68. Gibson, P.R. Increased gut permeability in crohn's disease: Is tnf the link? Gut 2004, 53, 1724-1725. [CrossRef]

69. Bouma, G.; Strober, W. The immunological and genetic basis of inflammatory bowel disease. Nat. Rev. Immunol. 2003, 3, 521-533. [CrossRef]

70. Xavier, R.J.; Podolsky, D.K. Unravelling the pathogenesis of inflammatory bowel disease. Nature 2007, 448, 427-434. [CrossRef]

71. Weber, C.R.; Turner, J.R. Inflammatory bowel disease: Is it really just another break in the wall? Gut 2007, 56, 6-8. [CrossRef]

72. Xu, P.; Elamin, E.; Elizalde, M.; Bours, P.P.H.A.; Pierik, M.J.; Masclee, A.A.M.; Jonkers, D.M.A.E. Modulation of intestinal epithelial permeability by plasma from patients with crohn's disease in a three-dimensional cell culture model. Sci. Rep. 2019, 9, 2030. [CrossRef] [PubMed]

73. Wang, F.; Schwarz, B.T.; Graham, W.V.; Wang, Y.; Su, L.; Clayburgh, D.R.; Abraham, C.; Turner, J.R. Ifn-gamma-induced tnfr2 expression is required for tnf-dependent intestinal epithelial barrier dysfunction. Gastroenterology 2006, 131, 1153-1163. [CrossRef] [PubMed]

74. Mohajeri, M.H.; La Fata, G.; Steinert, R.E.; Weber, P. Relationship between the gut microbiome and brain function. Nutr. Rev. 2018, 76, 481-496. [CrossRef] [PubMed]

75. Henson, M.A.; Phalak, P. Microbiota dysbiosis in inflammatory bowel diseases: In silico investigation of the oxygen hypothesis. BMC Syst. Biol. 2017, 11, 145. [CrossRef]

76. Calin, A.; Porta, J.; Fries, J.F.; Schurman, D.J. Clinical history as a screening test for ankylosing spondylitis. JAMA 1977, 237, 2613-2614. [CrossRef]

77. Martinez-Gonzalez, O.; Cantero-Hinojosa, J.; Paule-Sastre, P.; Gomez-Magan, J.C.; Salvatierra-Rios, D. Intestinal permeability in patients with ankylosing spondylitis and their healthy relatives. Br. J. Rheumatol. 1994, 33, 644-647. [CrossRef]

78. Ciccia, F.; Guggino, G.; Rizzo, A.; Alessandro, R.; Luchetti, M.M.; Milling, S.; Saieva, L.; Cypers, H.; Stampone, T.; Di Benedetto, P.; et al. Dysbiosis and zonulin upregulation alter gut epithelial and vascular barriers in patients with ankylosing spondylitis. Ann. Rheum. Dis. 2017, 76, 1123-1132. [CrossRef] 
79. Luo, X.M.; Edwards, M.R.; Mu, Q.; Yu, Y.; Vieson, M.D.; Reilly, C.M.; Ahmed, S.A.; Bankole, A.A. Gut microbiota in human systemic lupus erythematosus and a mouse model of lupus. Appl. Environ. Microbiol. 2018, 84, e02288-17. [CrossRef]

80. Tsokos, G.C. Systemic lupus erythematosus. N. Engl. J. Med. 2011, 365, 2110-2121. [CrossRef]

81. Nockher, W.A.; Wigand, R.; Schoeppe, W.; Scherberich, J.E. Elevated levels of soluble cd14 in serum of patients with systemic lupus erythematosus. Clin. Exp. Immunol. 1994, 96, 15-19. [CrossRef]

82. de Oliveira, G.L.V.; Leite, A.Z.; Higuchi, B.S.; Gonzaga, M.I.; Mariano, V.S. Intestinal dysbiosis and probiotic applications in autoimmune diseases. Immunology 2017, 152, 1-12. [CrossRef] [PubMed]

83. Esmaeili, S.A.; Mahmoudi, M.; Momtazi, A.A.; Sahebkar, A.; Doulabi, H.; Rastin, M. Tolerogenic probiotics: Potential immunoregulators in systemic lupus erythematosus. J. Cell Physiol. 2017, 232, 1994-2007. [CrossRef] [PubMed]

84. Fasano, A. Pathological and Therapeutical Implications of Macromolecule Passage through the Tight Junction. In Tight Junctions; CRC Press: Boca Raton, FL, USA, 2001; pp. 715-740.

85. Tio, T.L.; Tytgat, G.N. Endoscopic ultrasonography of normal and pathologic upper gastrointestinal wall structure. Comparison of studies in vivo and in vitro with histology. Scand. J. Gastroenterol. Suppl. 1986, 123, 27-33. [CrossRef] [PubMed]

86. Mariani, P.; Viti, M.G.; Montuori, M.; La Vecchia, A.; Cipolletta, E.; Calvani, L.; Bonamico, M. The gluten-free diet: A nutritional risk factor for adolescents with celiac disease? J. Pediatr. Gastroenterol. Nutr. 1998, 27, 519-523. [CrossRef]

87. Fasano, A. Surprises from celiac disease. Sci. Am. 2009, 301, 54-61. [CrossRef]

88. Fukuda, S.; Ohno, H. Gut microbiome and metabolic diseases. Semin. Immunopathol. 2014, 36, $103-114$. [CrossRef]

89. Cain, A.M.; Karpa, K.D. Clinical utility of probiotics in inflammatory bowel disease. Altern. Ther. Health Med. 2011, 17, 72-79.

90. Gomes, A.C.; Bueno, A.A.; de Souza, R.G.; Mota, J.F. Gut microbiota, probiotics and diabetes. Nutr. J. 2014, 13, 60. [CrossRef]

91. Cani, P.D.; Daubioul, C.A.; Reusens, B.; Remacle, C.; Catillon, G.; Delzenne, N.M. Involvement of endogenous glucagon-like peptide-1(7-36) amide on glycaemia-lowering effect of oligofructose in streptozotocin-treated rats. J. Endocrinol. 2005, 185, 457-465. [CrossRef]

92. Cani, P.D.; Knauf, C.; Iglesias, M.A.; Drucker, D.J.; Delzenne, N.M.; Burcelin, R. Improvement of glucose tolerance and hepatic insulin sensitivity by oligofructose requires a functional glucagon-like peptide 1 receptor. Diabetes 2006, 55, 1484-1490. [CrossRef]

Publisher's Note: MDPI stays neutral with regard to jurisdictional claims in published maps and institutional affiliations.

(C) 2020 by the authors. Licensee MDPI, Basel, Switzerland. This article is an open access article distributed under the terms and conditions of the Creative Commons Attribution (CC BY) license (http://creativecommons.org/licenses/by/4.0/). 